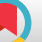

\title{
An Investigation of the Effect of Continuous Care Model on Compliance with Dietary and Fluid Restrictions in Hemodialysis Patients: A Clinical Trial Study
}

\author{
Saeid Hashemi (i) ${ }^{1,}$, Ali Tayebi ${ }^{2}$, Abolfazl Rahimi ${ }^{2}$ and Behzad Einollahi ${ }^{3}$ \\ ${ }^{1}$ Department of Nursing, Faculty of Nursing, Baqiyatallah University of Medical Sciences, Tehran, Iran \\ ${ }^{2}$ Department of Psychiatric Nursing, Nephrology and Urology Research Center, Baqiyatallah University of Medical Sciences, Tehran, Iran \\ ${ }^{3} \mathrm{Nephrology}$ and Urology Research Center, Baqiyatallah University of Medical Sciences, Tehran, Iran \\ "Corresponding author: MSc Student in Critical Care Nursing, Department of Nursing, Faculty of Nursing, Baqiyatallah University of Medical Sciences, Tehran, Iran. Email: \\ hashemi.saeid65@yahoo.com
}

Received 2018 December 11; Accepted 2018 December 19.

\begin{abstract}
Background: Compliance with dietary and fluid restrictions is an integral part of treatment in hemodialysis patients. In fact, nonadherence to these restrictions could entail serious consequences.

Objectives: The present study was conducted to explore the impact of continuous care model on compliance with dietary and fluid restrictions in these patients.

Methods: The current study was a clinical trial with a control group, which was carried out on 98 hemodialysis patients at two hospitals in Tehran. The subjects were chosen via purposive sampling and randomly assigned to the treatment and control groups. The treatment adherence questionnaire was completed by both groups in the pretest. Afterwards, in the treatment group, once the subjects were presented with the educational manual, a continuous care model was implemented for them. The model consisted of four stages, including awareness-raising, sensitization, control, and evaluation. At the end of three consecutive months, the questionnaire was completed. In the control group, the questionnaire was similarly completed except the subjects had not been exposed to any intervention. Data were collected using descriptive tests, chi-square, $t$-test, and a repeated measures design. The results were analyzed with the SPSS 21 software.

Results: The findings showed that the pattern of adherence to dietary and fluid restrictions in the two groups was statistically significant over time $(\mathrm{P}<0.001)$ such that changes in the intervention group were indicative of the positive effects of continuous care on compliance with dietary and fluid restrictions among hemodialysis patients.

Conclusions: By implementation of the continuous care model, the patients, through counseling and training, developed a greater adherence to their dietary and fluid restrictions. Hence, it is suggested for ICU nurses to make use of this model to prevent complications and improve quality of life of hemodialysis patients.
\end{abstract}

Keywords: Continuous Care Model, Dietary Compliance, Fluid Restriction Adherence, Hemodialysis

\section{Background}

Chronic kidney disease (CKD) is worldwide recognized as one of the general health problems that results in heightened costs as well as mortality rates (1). The CKD is an irreversible progressive disorder in the function or structure of kidneys (2). At the end of year 2015, the prevalence of end-stage renal disease (ESRD) in the world varied from country to country. Back then, the number of these patients was estimated as 352300 , which was expected to rise annually by $5 \%$ to $6 \%$. According to the report of the Iranian Consortium of Dialysis (ICD), mid-March, 2016, the population of ESRD patients, who received renal alterna- tive treatments reached 53000 in Iran (3). Patients with kidney failure urgently need dialysis and transplantation to survive (4). According to statistics released in 2015, a total of 27500 people used hemodialysis in Iran. This number ranged from 189 to more than 480 per million in different provinces (3). The main purpose of hemodialysis, similar to kidney function, is the recovery of intracellular and extracellular fluid environment (5). Although this treatment can prolong survival and improve patients' health, it cannot permanently replace the function of the kidneys and change the course of the disease (6). Therefore, renal patients have to grapple with many problems due to the process of disease and treatment, all of which disturb 
the patient's quality of life, cause depression, and sometimes lead to suicide and premature mortality (7). Despite the fact that hemodialysis increases the patient's life and enhances its quality, it cannot be effective enough without adherence to dietary restrictions (8). There is a relationship between mortality rate and non-compliance with dietary restrictions (9). Failure to follow the prescribed fluid regimen in these patients leads to weight gain between two dialysis sessions and complications, such as muscle cramps, shortness of breath, dizziness, anxiety, lung swelling, heart failure, and hypertension. On the other hand, failure to abide by a low-potassium diet confronts these patients with weakness, arrhythmia, cardiac arrest, and death (10). Reduction in blood albumin level is one of the key indicators of hospitalization rate as well as death rate (11). For this reason, patients need to adhere to specific dietary and fluid restrictions to survive (12). In a study by Kim et al. (13), most hemodialysis patients did not follow the dietary (82.4\% to $1.2 \%$ ) and fluid (74\% to $3.4 \%$ ) restrictions, which appeared to originate in the lack of awareness among these patients. Since education can play a remarkable role in promoting adherence to dietary and fluid restrictions in hemodialysis patients, it reduces costs and improves the quality of life provided that such training is tailored to the real needs of these patients (14). Therefore, it is vital to use a model appropriate to the condition of these patients. In Iran, a continuous care model has been designed and evaluated by Ahmadi (15) in relation to chronic coronary patients. This model has four stages, including awareness-raising, sensitization, control, and evaluation. This model introduces the patient as the focus of a continuing and effective care in the health process. Continuous care is a regular and mutual process for establishing effective interactions between the patient and the nurse as the care provider. The purpose is to understand the needs and difficulties of patients, sensitize them to cultivate ongoing health behaviors, and help them maintain their recovery and promote their health. This care is completely relevant to the characteristics and dynamics of chronic diseases (15). It is primarily intended to design and develop a program that could subsequently adopt a better performance with regards to their health status so that it can be easier to control the disease and its possible complications.

\section{Objectives}

The purpose of the current study was to determine the effect of continuous care model on adhering to dietary and fluid restrictions in case of hemodialysis patients.

\section{Methods}

This was a two-group clinical trial, which was conducted at two hospitals of Tehran. The subjects were selected through purposive sampling and randomly allocated to either the control or treatment group. Data collection instruments included: (1) A questionnaire developed according to the research objectives and demographic characteristics of patients including age, gender, marital status, and duration of dialysis; (2) Kim's end-stage renal disease adherence questionnaire used to assess compliance with dietary (eight questions) and fluid (ten questions) restrictions. The scores of this tool ranged between 0 and 200. Question 5 assesses compliance with the fluid regimen and questions 13 and 14 measure the perception and level of understanding of patients with respect to abiding by dietary and fluid restrictions. Khalili et al. (16), reported the reliability of this questionnaire to be $75 \%$ as obtained via the Cronbach's alpha coefficient. The study samples comprised of patients with CKD, who were receiving hemodialysis treatment. Altman's nomogram was used to estimate the sample size. Considering $\alpha$ of 0.05 and standard deviation of $90 \%$ derived from the study of Hashemi et al. (17), 90\% confidence interval, and 10\% dropout, the number of samples for each group was estimated as 50. After selecting the research subjects, according to the inclusion criteria, the authors introduced themselves to the patients and obtained their consent to participate in the research. Next, the participants were randomly assigned to either the control or treatment group. Then, for about 15 to 20 minutes, the physical and psychological status of each person was examined individually without blinding anyone. Afterwards, they were given the demographic questionnaire. At the time of completion of the demographic questionnaire, the researcher was present to answer the patients' possible questions. The second part of the questionnaire was related to self-reporting of personal adherence to dietary and fluid restrictions, and was filled through interviewing the patients. The average time required to complete the questionnaire was about 20 to 30 minutes. After necessary arrangements were made concerning various steps of the project, the questionnaires were completed by both groups. The continuous care model consisted of four stages of awarenessraising, sensitization, control, and evaluation, and it was implemented over the course of 12 weeks (Table 1 ). The first and second stages were administered during the first three weeks. Specifically, the awareness-raising stage was aimed at identifying patients' problems and motivating them through providing a training manual, individual counseling, and explanations on the necessity of sustaining the care-therapeutic relationship with the researcher. Sensiti- 
zation was carried out to engage the patient and their family in implementing the care program. This was achieved through group discussion, individual counseling, lectures, as well as question-and-answer sessions. Other related measures were also taken to train patients to control symptoms and complications and observe dietary and fluid restrictions. The number of intervention sessions (each lasting between 30 and 45 minutes) was four to six, depending on the particular needs of subjects and their level of awareness. All educational interventions were performed in the presence of the patient's family and, if necessary, they would be referred to the nephrology specialist.

During the remaining nine weeks, the control and evaluation steps were completed. At the control stage, patients were examined on a weekly basis over the telephone or in person, and in case of any ambiguity or new problems, appropriate counseling and training were provided and the process of care was continued. In the evaluation stage, which was conducted after each of the three previous steps, new challenges and needs of patients were recognized to sustain the care process. In addition, the effectiveness of interventions on meeting patients' needs and resolving their problems was gauged. At the end of the intervention, the questionnaires pertaining to compliance with dietary and fluid restrictions were completed by both treatment and control groups. The control group received routine care. The questionnaires were completed again in both groups at the end of the second and third months after the intervention. Descriptive statistics and repeated measures analysis of variance (ANOVA) were employed. Data were analyzed using SPSS 21, and the level of statistical significance was set at $\mathrm{P}<0.05$.

\section{Results}

A total of 100 individuals took part in this research. They were randomly assigned to the treatment (n: 5) and control (n: 50) groups. However, at the beginning of the second month, two patients in the treatment group were excluded because of their reluctance to cooperate further. Thus, the study was continued with 48 patients in this group and 50 others in the control group. The mean age of subjects in the treatment and control group was $62.33 \pm$ 14.22 and $59.50 \pm 16.14$ years, respectively. Besides, the duration of dialysis in the treatment and control group was $33.65 \pm 33.13$ and $31.50 \pm 30.22$ months. Married subjects constituted $49 \%$ and $52.1 \%$ of the treatment and control groups, respectively. In terms of gender, $51 \%$ of the treatment group and $49 \%$ of the control group were male. Also, the results of statistical tests displayed that there was no significant difference between the treatment and control groups in terms of demographic variables, which could affect the outcome of the study. The results of repeated measures analysis of variance (ANOVA) indicated that group interaction and time are significant in terms of compliance with dietary and fluid restrictions. The change pattern of adherence to dietary and fluid restrictions were not the same in the two groups. Thus, the average adherence to dietary and fluid regimen in the two groups at posttests one, two, and three (i.e. one, two, and three months post-intervention) was significantly different(Table 2). The change pattern of the treatment group tended towards increasing compliance to the related regimens.

\section{Discussion}

The results of this study suggests that there was a significant difference between the mean score of adherence to dietary and fluid restrictions in hemodialysis patients before and after the intervention. In general, the reason for this statistical difference can be attributed to the effect of implementing the continuous care model, which has significantly boosted adherence to dietary and fluid regimens. This means that individual, group, and family training has assisted patients and their families to enhance their dietary status and abide by their fluid restrictions. Yu et al. (18) studied depression and non-compliance with prescriptions in peritoneal dialysis patients and found that $20 \%$ of individuals did not follow their dietary and medicinal regimen because of forgetfulness, while $15 \%$ to $25 \%$ of patients intentionally ignored their restrictions. Liang et al. (19), addressing the restriction of fluid and salt intake in hemodialysis patients with cardiac problems, proposed that limiting the amount of fluid and salt intake in these individuals can reduce left ventricular hypertrophy. Furthermore, in a systematic review carried out by Moosavinasab et al. (20) on the effects of continuous care on various health outcomes of chronic patients, the results confirmed the positive impact of such care on cardiovascular, diabetic, renal, and hemodialysis patients. In this study, the effects of continuous care model on changes and continuity of compliance with dietary restrictions were repeatedly evaluated for three months after the intervention. The results of other similar studies on hemodialysis patients are consistent with those of the present research. In this regard, one may refer to the positive impact of continuous care on patients' sleep (21), quality of life (22), and diet (23).

\subsection{Conclusions}

Regarding the results of this study, it can be concluded that using the continuous care model triggers a significant difference in compliance with dietary and fluid re- 


\begin{tabular}{ll}
\hline Table 1. The Content of the Intervention on the Basis of Different Stages of Continuous Care \\
\hline Stage & Intervention Topic \\
\hline Awareness-raising & $\begin{array}{l}\text { Understanding patient's problems, explaining the importance of continuous care, holding 15 - 30-minute sessions } \\
\text { Sensitization }\end{array}$ \\
$\begin{array}{l}\text { Sensitizing the patient to keep in touch with the researcher, holding } 4 \text { - } 6 \text { sessions of individual and group counseling for patients and their } \\
\text { family }\end{array}$ \\
$\begin{array}{l}\text { Weekly follow-up by telephone and in person, and providing necessary training and counseling } \\
\text { Evaluation }\end{array}$ & $\begin{array}{l}\text { Evaluating all stages and assessing the effectiveness of educational counseling interventions, continuing the care process, and identifying new } \\
\text { problems/needs of patients }\end{array}$ \\
\hline
\end{tabular}

Table 2. Mean and Standard Deviation of Adherence to Dietary and Fluid Restrictions Among Hemodialysis Patients in the Treatment and Control Groups (Measured Four Times) $)^{\mathrm{a}}$

\begin{tabular}{|c|c|c|c|c|c|c|}
\hline \multirow[t]{2}{*}{ Time } & \multicolumn{3}{|c|}{ Adherence to Fluid Regimen } & \multicolumn{3}{|c|}{ Adherence to Dietary Regimen } \\
\hline & Control $(\mathbf{N})$ & Treatment $(\mathbf{N})$ & $\mathbf{P}$ & Control & Treatment & $\mathbf{P}$ \\
\hline Before intervention/pretest & $109 \pm 4.8$ & $148.95 \pm 5.66$ & 0.06 & $127 \pm 6.09$ & $148.95 \pm 6.04$ & 0.08 \\
\hline Posttest 1 & $111.16 \pm 5.52$ & $166.66 \pm 3.74$ & $<0.001$ & $117 \pm 6.64$ & $156.25 \pm 4.85$ & $<0.001$ \\
\hline Posttest 2 & $113 \pm 5.49$ & $183.33 \pm 3.43$ & $<0.001$ & $116 \pm 6.76$ & $177.08 \pm 3.63$ & $<0.001$ \\
\hline Posttest 3 & $112 \pm 4.18$ & $189.58 \pm 2.96$ & $<0.001$ & $125 \pm 6.58$ & $184.37 \pm 3.38$ & $<0.001$ \\
\hline
\end{tabular}

${ }^{\text {a }}$ Values are expressed as mean $\pm \mathrm{SD}$.

strictions among hemodialysis patients. The implementation of this indigenous model is associated with increased adherence to dietary and fluid regiments in hemodialysis patients. Therefore, it can be inferred that applying a continuous care model by conducting extensive studies on hemodialysis patients in clinical settings can yield positive outcomes for their clinical status.

\section{Acknowledgments}

Hereby, the authors thank all patients, who earnestly participated in this research (IRCT 2014012816400N). The researchers also appreciate the support of the Nursing Department, the Research Vice Presidency of the faculty, and the Nephrology and Urology Research Center of Baqiyatallah University of Medical Sciences.

\section{Footnotes}

Authors' Contribution: All authors participated in the study design, concepts, and revising of the manuscript.

Clinical Trial Registration: IRCT 2014012816400N.

Conflict of Interests: There was no conflict of interest in this study.

Funding/Support: Nursing Department, the research vice presidency of the faculty, and the Nephrology and Urology Research Center of Baqiyatallah University of Medical Sciences.

\section{References}

1. Alves KB, Guilarducci NV, Santos TDR, Baldoni AO, Otoni A, Pinto SWL, et al. Is quality of life associated with compliance to pharmacoterapy in patients with chronic kidney disease undergoing maintenance hemodialysis? Einstein (Sao Paulo). 2018;16(1):eAO4036. doi: 10.1590/s1679-45082018ao4036. [PubMed: 29694614]. [PubMed Central: PMC5968805].

2. Levin A, Stevens PE, Bilous RW, Coresh J, De Francisco AL, De Jong PE, et al. Kidney disease: Improving global outcomes (KDIGO) CKD work group. KDIGO 2012 clinical practice guideline for the evaluation and management of chronic kidney disease. Kidney Int Suppl. 2013;3(1):150. doi: 10.1038/kisup.2012.73.

3. Kazemi S, Didarlo A, Khalkhali H, Feizi A. [Studying the relationship between self-efficacy and dietary adherence, in patients under hemodialysis]. J Urmia Nurs Midwifery Facult. 2018;15(11):835-42. Persian.

4. Naalweh KS, Barakat MA, Sweileh MW, Al-Jabi SW, Sweileh WM, Zyoud $\mathrm{SH}$. Treatment adherence and perception in patients on maintenance hemodialysis: A cross-sectional study from Palestine. BMC Nephrol. 2017;18(1):178. doi: 10.1186/s12882-017-0598-2. [PubMed: 28558719] [PubMed Central: PMC5450383].

5. Chaykovska L, Tsuprykov O, Hocher B. Biomarkers for the prediction of mortality and morbidity in patients with renal replacement therapy. Clin Lab. 2011;57(7-8):455-67. [PubMed: 21888009].

6. Ebrahimi H, Sadeghi M. [The effect of dietary regimen education on the laboratory variables in hemodialysis patients]. J Nurs Educat 2014;2:12-22. Persian.

7. Hasanzadeh F, Shamsoddini S, Karimi Moonaghi H, Ebrahimzadeh S. [A comparison of face to face and video-based education on attitude related to diet and fluids adherence in hemodialysis patients]. Horizon Med Sci. 2011;17(3):34-43. Persian.

8. Baljani ES, Habibzadeh H, Rahimi J, Azimpour A, Salimi S. [Effect of self management programs on dietary adherence and interdialytic weight gain in patients undergoing hemodialysis]. J Urmia Nurs Midwifery Fac. 2013;11(4). Persian. 
9. Umeukeje EM, Merighi JR, Browne T, Victoroff JN, Umanath K, Lewis JB, et al. Self-motivation is associated with phosphorus control in end-stage renal disease. J Ren Nutr. 2015;25(5):433-9. doi: 10.1053/j.jrn.2015.03.001. [PubMed: 25912398]. [PubMed Central: PMC4546917].

10. Walsh E, Lehane E. An exploration of the relationship between adherence with dietary sodium restrictions and health beliefs regarding these restrictions in Irish patients receiving haemodialysis for endstage renal disease. J Clin Nurs. 2011;20(3-4):331-40. doi: 10.1111/j.13652702.2010.03348.x. [PubMed: 21219516].

11. Tranter S. Review of haemodialysis for nurses and dialysis personnel. Renal Soc Australas J. 2016;12(1):34.

12. Rambod M, Peyrovi H, Sareban MT, Rafii F. [Relationship of selfefficacy with therapeutic regimen and clinical/laboratory outcomes in hemodialysis patient]. Iran J Nurs. 2010;22(62):41-7. Persian.

13. Kim Y, Evangelista LS, Phillips LR, Pavlish C, Kopple JD. The end-stage renal disease adherence questionnaire (ESRD-AQ): Testing the psychometric properties in patients receiving in-center hemodialysis. Nephrol Nurs J. 2010;37(4):377-93. [PubMed: 20830945]. [PubMed Central: PMC3077091].

14. Jafari F, Hashemi N, Reisi M. [The effect of diet training on variations in blood pressure, weight, and some biochemical factors in hemodialysis patients: A clinical trial]. J Clin Nurs Midwifery. 2015;3(4):13-9. Persian.

15. Ahmadi F. Design and evaluation of continuous care model in the management of patients with coronary artery disease [dissertation]. Tehran University of Medical Sciences; 2001. Persian.

16. Khalili F, Eslami AA, Farajzadegan Z, Hassanzadeh A. [The association between social-psychological factors and treatment adherence be- haviors among maintenance hemodialysis patients in Isfahan, Iran: A conceptual framework based on social cognitive theory]. Health Sys Res. 2011;7(3):278-90. Persian.

17. Hashemi S, Tayebi A, Rahimi A, Einollahi B. Examining the effect of continuous care model on adherence to dietary regimen among patients receiving hemodialysis. Iran J Crit Care Nurs. 2015;7(4):215-20.

18. Yu ZL, Yeoh LY, Seow YY, Luo XC, Griva K. Evaluation of adherence and depression among patients on peritoneal dialysis. Singapore Med J. 2012;53(7):474-80. [PubMed: 22815017].

19. Liang X, Wang W, Li H. Water and sodium restriction on cardiovascular disease in young chronic hemodialysis patients. Chin Med J (Engl). 2013;126(9):1667-72. [PubMed: 23652048].

20. Moosavinasab SMM, Vahedian-Azimi A, Salesi M, Vahedi E, Karimi Zarchi AA, Khosh Fetrat M, et al. [A review of 17 years of application of a continuous care model on the consequences of acute and chronic diseases: Describing and assessing the quality of methodology of papers]. J Military Med. 2018;20(1):27-55. Persian.

21. Alizadeh SM, Sadeghi H, Haghdoost AA, Azizzadeh Forouzi M. Effect of applying continuous care model on sleepiness in patient undergoing hemodialysis in Shahinshahr hemodialysis center in 2009. J Shahid Sadoughi Univ Med Sci. 2013;20(5):537-46.

22. Rahimi A, Ahmadi F, Gholyaf M. [Effects of applying continuous care model on quality of life in hemodialysis patients]. Razi J Med Sci. 2006;13(52):123-34. Persian.

23. Brothers S, Mohammad A, Memorial B. [The effect of diet education on the laboratory parameters and weight gain between dialysis sessions in patients treated with hemodialyzing holder]. Univ Med Sci. 2007;8(1):20-7. Persian. 